\title{
PCA analysis of the nighttime anomaly in far-from-geomagnetic pole regions from VTEC GNSS data
}

\author{
A. Meza ${ }^{1,2}$, M. P. Natali, ${ }^{1,2^{*}}$ and L. I. Fernández ${ }^{1,2}$
}

\begin{abstract}
The Weddell Sea Anomaly (WSA) is defined when the nighttime plasma density is greater than the daytime density in the area near the Weddell Sea, more specifically in the region limited by $50^{\circ} \mathrm{S}-70^{\circ} \mathrm{S}$ in latitude and $225^{\circ} \mathrm{E}-315^{\circ} \mathrm{E}$ in longitude. A similar ionospheric anomaly is also observed near the Okhotsk Sea in the northern hemisphere, and such a feature was named as Okhotsk Sea Anomaly (OSA).

The objective of this work is to infer possible physical causes of the WSA and OSA phenomena. To that end, we applied the principal component analysis (PCA) technique to the vertical total electron content (VTEC) from global International GNSS Service (IGS) in order to analyze the temporal and spatial variations of the ionosphere during noon and night in far-from-magnetic pole regions, during a 3-year period at high (2000-2002) and low (2006-2008) solar activity conditions.

The first mode of PCA applied on VTEC scattering represents on average the $93 \%$ of the total VTEC variability. Thus, the PCA expansions up to mode 1 resulted enough to show WSA and OSA during summer solstices in both solar activity conditions, as well as WSA during spring equinox during low solar activity. Besides, the analysis of the temporal variations of these first modes should provide the interpretation of a probable physical explanation to the observed anomalies. We conclude that the main contributors to the anomalies should be a combination of the same physical mechanisms that explain annual variation and semiannual anomaly in that regions located far from the magnetic poles.
\end{abstract}

Keywords: Principal component analysis; Global IGS VTEC maps; Anomalies; Weddell Sea Anomaly

\section{Background}

Having the greatest concentration of free electrons, the F2 region of the ionosphere is of huge interest in radio propagation. Among its characteristics, it is the most variable, anomalous, and difficult region to predict. Major deviations from Chapman theory (Chapman 1931), which is based on the regular variability of the electron concentrations with solar zenith angles, are named "anomalies." Many ionospheric researchers (Bellchambers and Piggott 1958; Penndorf 1965; Dudeney and Piggott 1978) studied the F2 layer over Antarctica using ground-based ionosondes. They found a region near the Antarctic Peninsula

\footnotetext{
* Correspondence: paula@fcaglp.unlp.edu.ar

${ }^{1}$ Facultad de Ciencias Astronómicas y Geofísicas, Universidad Nacional de La Plata, Paseo del Bosque s/n, 1900 La Plata, Argentina

${ }^{2}$ Consejo Nacional de Investigaciones Científicas y Técnicas (CONICET), Av. Rivadavia 1917, Buenos Aires, Argentina
}

including the Weddell Sea area with an anomalous behavior in f0F2. This phenomenon was called the Weddell Sea Anomaly (WSA). The WSA is characterized by higher electron densities during the night than during the day, where the authors considered night the time interval between 10 p.m. to 4:00 a.m. local time (LT) and day the interval of 10:00 a.m. to 6:00 p.m. LT (Lin et al. 2009). Recently, several authors (Horvath and Essex 2003; Horvath 2006; Burns et al. 2008; Lin et al. 2009; Jee et al. 2009; He et al. 2009; Liu et al. 2010) based on remote sensing and ionosonde data show that the WSA extends in a region located west to the Antarctica Peninsula.

There are several physical mechanisms proposed that may contribute to the formation of the WSA. In the 1960s, Penndorf (1965) associated the anomaly with high-latitude convection patterns, but later, this theory 
was rejected because the region near the Weddell Sea is located at mid-geomagnetic latitudes, which means high geographic latitudes. Later, this phenomenon was associated with the longer daylight hours at these latitudes during summer and a combination of neutral winds blowing equatorward from day to night and from summer to winter (Dudeney and Piggott 1978). Horvath and Essex (2003), using global TOPEX/Poseidon observations and based on the previous results in Dudeney and Piggott (1978), demonstrated that this anomaly is related with the Equatorial Ionization Anomaly (EIA). They also showed the estimated size of the anomaly and asseverated that it is located west of the Antarctic Peninsula over the Bellingshausen Sea and not over the Weddell Sea. In fact, the authors suggested that the correct name should be Bellingshausen Sea Anomaly instead of WSA. Lin et al. (2009) described a three-dimensional structure of the WSA by using ionospheric vertical density profiles observed by the FORMOSAT-3/COSMIC. The authors point out that the major reasons for producing this anomalous characteristic may be in the increment of the electron density at the southern part of the EIA along with stronger neutral winds to the equator at longitude of $90^{\circ} \mathrm{W}$ and an offset of the magnetic equator to the south and the magnetic declination to the east. They also found a similar anomalous feature in the northern hemisphere $\left(40^{\circ} \mathrm{N}-60^{\circ} \mathrm{N}\right.$ in latitude and $120^{\circ} \mathrm{E}-140^{\circ} \mathrm{E}$ in longitude) in June solstice. This result confirms that the hypothesis of the offset between magnetic and geographic equators may be a sustaining feature that leads to the formation of the WSA. Liu and Yamamoto (2011) and Lin et al. (2010) called this effect as "Midlatitude Summer Night Anomaly" (MSNA). The work by $\mathrm{He}$ et al. (2009) on this anomaly based on FORMOSAT/ COSMIC data concludes that a possible cause for the $\mathrm{NmF} 2$ and the hmF2 increases could be due to the thermospheric wind effect. Furthermore, it states that photoionization is a first-order effect during the local summer and that the WSA arises from the evening enhancements induced by the winds and favored by the geometry of the magnetic field.

Chen et al. (2011) used SAMI2 model to simulate the WSA, and they identified various causal mechanisms. Their major findings about WSA formation are as follows: the equatorward neutral wind is the critical driver, the plasmaspheric downward flux is another driver but not a critical one, and both the magnetic offset and the declination of the magnetic field are very important. All these results suggested various possible physical drivers that may contribute to the formation of the WSA, but their relative importance is not clearly identified.

The Global Ionospheric Maps (GIMs) are computed by distinguished research groups dedicated to ionospheric studies with GPS observations. The GIM files are available in the IONEX (IONosphere map EXchange) format (Schaer et al. 1998), and they contain the vertical total electron content (VTEC) values on a $2.5^{\circ} \times$ $5^{\circ}$ grid at regular intervals of latitude and longitude.

Principal component analysis (PCA) is a useful numerical technique for the investigation of the spatial and temporal variability of physical phenomena. This mathematical procedure is based on orthogonal transformation from a set of correlated variables into a set of uncorrelated variables, the last ones called principal components. Many authors have used this numerical tool for ionospheric studies (Zhao et al. 2005; Meza and Natali 2008).

In this paper, we show the existence of the Weddell Sea Anomaly and an equivalent feature in the northern hemisphere named as Okhotsk Sea Anomaly (OSA), taking into account their geomagnetic, seasonal, and solar activity dependences. To this aim, the anomalies were detected from the spatial and temporal ionospheric variability revealed through PCA application to the GIMs. Our work proposes to consider the VTEC values at 22 LT and at 12 LT in both regions (far from the geomagnetic polar areas) and for two different solar conditions: during 2000-2002 accounting for high solar activity and 2006-2008 for low solar activity, respectively. When the difference between VTEC at night and VTEC at midday is positive, the anomaly is recorded. Thus, a lineal combination of these two parameters should obey to the same physical causes that produce the variations of the VTEC night and VTEC midday separately. This relation is studied at different points belonging to the respective regions and for each day during the periods of our analysis. The "Methods" section describes data arrangements prior to PCA application as well as the main steps of the numerical procedure. In the "Results and discussion" section, we analyze the temporal and spatial behavior of VTEC values at night and midday separately using PCA, and we present a discussion about the physical framework and the relative importance of the different excitation mechanisms. Finally, the conclusions are presented.

\section{Methods}

\section{Data selection}

Global VTEC maps from International GNSS Service (IGS) were used in this work. These maps provide ionospheric electron content information every $2 \mathrm{~h}$ in a grid of $2.5^{\circ}$ in latitude and $5^{\circ}$ in longitude.

In order to represent high and low solar activity periods, two intervals of 3 years each were selected: 2000 to 2002 and 2006 to 2008, respectively. Because we are interested in analyzing the ionospheric response to similar solar radiation conditions on different locations, the data set was ordered to obtain one map per day at two 
selected local times: 12 LT (noon) and 22 LT (night). Thus, the initial data set of 13,152 maps for high solar activity and the same for low solar conditions was reduced to a set of 1096 maps for each 3-year period. The reordering scheme was as follows: assuming that the ionosphere does not change in a 2-h window, we considered slices of $30^{\circ}$ each centered on the same local time, from all the maps for each day. Then, the slices were merged into a new VTEC map corresponding to their central longitude. Thus, following this procedure, a new VTEC map was built matching to the local time selected (for example, $12 \mathrm{LT}$ ).

For the analysis, we built new VTEC maps corresponding to local time $12 \mathrm{LT}$ and $22 \mathrm{LT}$. Two regions defined between $40^{\circ} \mathrm{W}-140^{\circ} \mathrm{W}$ in longitude and $50^{\circ} \mathrm{S}-$ $70^{\circ} \mathrm{S}$ in geographic latitude for the southern hemisphere and the other one in the northern hemisphere, which is limited by $90^{\circ} \mathrm{E}-170^{\circ} \mathrm{E}$ in longitude and $40^{\circ} \mathrm{N}-70^{\circ} \mathrm{N}$ in latitude, were selected in order to show the WSA and OSA properly.

\section{PCA application}

Principal component analysis (PCA) is a powerful technique for multivariate time series analysis. The technique assumes that a set of observed variables are correlated through first-order linear dependencies and provides a way to build a new set of uncorrelated variables that allow the reconstruction of the complete observed data set. This feature is a strong motivation to use PCA for there may be a good chance that a small set of uncorrelated variables that completely represents a data set can also be related to a combination of a small number of independent physical phenomena.

The set of uncorrelated variables provided by PCA is an orthonormal base of minimum dimension. The shape of these eigenvectors is determined by the observation set. Thus, they may not necessarily be described by means of simple mathematical expressions. This is the reason why PCA is a well-suited technique for multivariate data set analysis on which the underlying phenomena are not known to be a superposition of well-known components that would point other techniques (e.g., Fourier analysis) as more adequate.

We present a brief description of the technique; further details about algebraic foundations of PCA can be found in Preisendorfer (1988) and Wackernagel (1998).

Let $V$ contain the VTEC information coming from GIMs as was described in the "Data selection" section, where the columns and rows are the temporal and the spatial variation, respectively,

$$
\begin{gathered}
V_{\text {tec } i j}=v_{i j}(t, x)=\left(\begin{array}{ccc}
V_{\text {tec11 }} & \cdots & V_{\text {tec } 1 m} \\
\vdots & \ddots & \vdots \\
V_{\text {tecn1 }} & \cdots & V_{\text {tec } n m}
\end{array}\right) \\
i=1, \ldots, n ; j=1, \ldots, m
\end{gathered}
$$

Applying PCA, first, we subtract the time average on each row $\left(\overline{v_{i j}}\right)$.

$$
V^{\prime}=v^{\prime}{ }_{i j}(t, x)=v_{i j}(t, x)-\bar{v}_{i j}(x)
$$

This new data set has zero mean.

In a second step, we define the scatter matrix, $S$, as:

$$
S=V^{\prime \mathrm{T}} V^{\prime}
$$

As $S$ is a square matrix, it has a set of orthonormal eigenvectors, and this represent the last step. This procedure allow to represent $S$ in a new basis. Using the eigenvectors $\mathbf{e}_{j}$, it is possible to construct the principal components $\mathbf{a}_{j}$ of the data set:

$$
A=V^{\prime \mathrm{T}} E \text { or } \mathbf{a}_{j}=v^{\prime}{ }_{i j}^{\mathrm{T}} \mathbf{e}_{j}
$$

where the columns of $E,\left\{\mathbf{e}_{1}, \mathbf{e}_{2}, \ldots, \mathbf{e}_{n}\right\}$, are the eigenvectors of $S$.

Multiplying Eq. (4) from the right by $E^{\mathrm{T}}$, and using the property that $E E^{\mathrm{T}}=E^{\mathrm{T}} E=I$, the original zero-mean data set can be expressed in the following form:

$$
A E^{\mathrm{T}}=V^{\prime \mathrm{T}} \text { or } \mathbf{a}_{j} \mathbf{e}_{j}^{\mathrm{T}}=v^{\prime}{ }_{i j}^{\mathrm{T}}
$$

The original data set Eq. (1) can be written with PCA as:

$$
v_{i j}^{\mathrm{T}}=\bar{v}_{i j}^{\mathrm{T}}+\mathbf{a}_{j} \mathbf{e}_{j}^{\mathrm{T}}
$$

The eigenvectors $\left(\mathbf{e}_{j}\right)$ represent the spatial structure of the ionospheric variability while the coefficients $\left(\mathbf{a}_{j}\right)$ characterize the temporal information called principal components. Thus, we call modes of variability to eigenvector and principal components together. The eigenvalue sizes are used to order the modes from biggest to smallest. As the eigenvalue decreases very fast, a few modes are enough to represent most of the original signal.

\section{Results and discussion}

VTEC maps from IGS were used to show the WSA and OSA occurring in the southern and northern hemispheres, respectively. Both anomalies are characterized by higher electron density at night than at noon.

Figure $1 \mathrm{a}, \mathrm{b}$ shows monthly averaged difference between VTEC at $22 \mathrm{LT}$ and $12 \mathrm{LT}$ over the 3 years for high and low solar activity, respectively, for the WSA region. The anomaly is clearly shown in January, February, November, and December (summer solstice) both for high and low solar activity. In addition, the maps also 


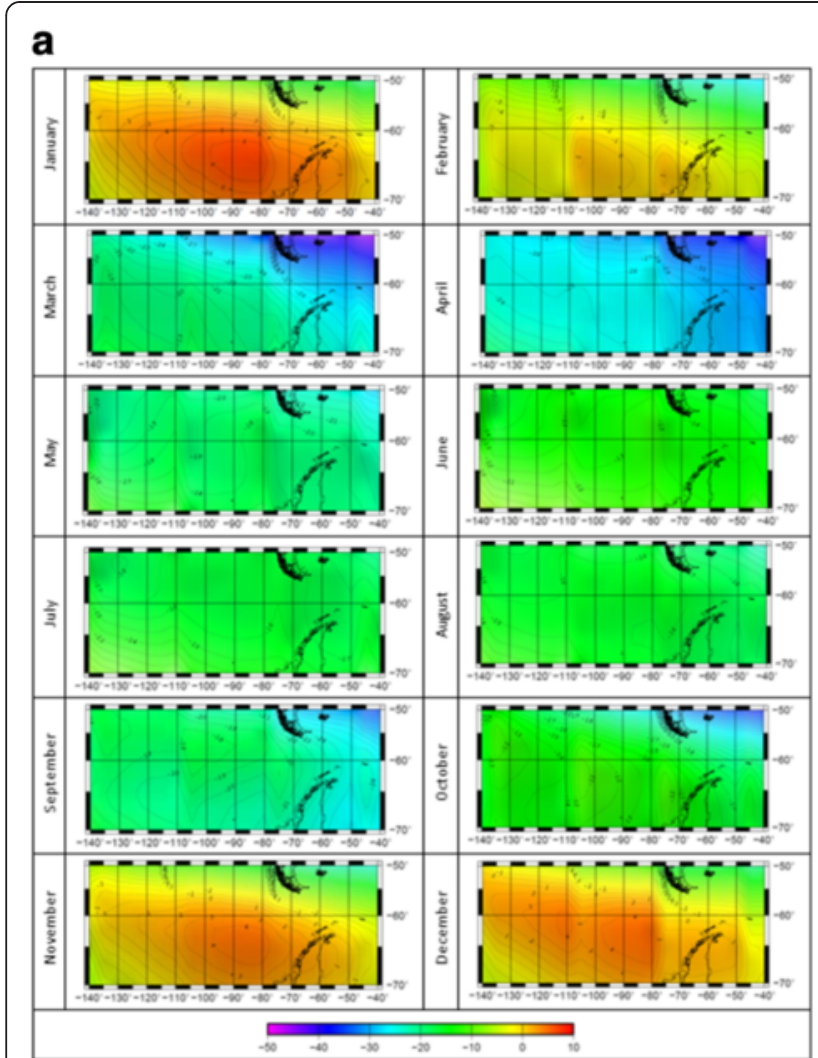

b

Fig. 1 Weddell Sea region. a Differences between monthly averaged VTEC values at night and the respective ones at midday for high solar activity (2000-2002). Positive values indicate the anomaly. Colorbar units are in TECU. b Differences between monthly averaged VTEC values at night and the respective ones at midday for low solar activity (2006-2008). Positive values indicate the anomaly. Colorbar units are in TECU

show a much slighter anomaly during October (equinox) in low solar activity.

Figure $2 \mathrm{a}, \mathrm{b}$ shows monthly averaged difference between VTEC at $22 \mathrm{LT}$ and 12 LT over the 3 years for high and low solar activity, respectively, for the OSA region. OSA anomaly can be seen in June and July (summer solstice) for high solar activity and in May, June, and July (summer solstice) for low solar activity. OSA anomaly is smaller and the values are lower than WSA in summer solstice and is absent in the equinox. Equivalent features were observed by Lin et al. (2009) using Global VTEC maps.

In the following, we analyze the temporal and spatial behavior of VTEC values at night and noon separately using PCA. Eight 3-year daily map series as described in the "Data selection" section were analyzed using this numerical technique. For WSA, daily map series for years 2000-2002 and 2006-2008 and for local times 12 LT and 22 LT were computed, producing four maps. For OSA region, another four equivalent map series were selected.

Figure $3 \mathrm{a}, \mathrm{b}$ shows the percentage of variability represented by the first ten modes for the eight 3-year map series for the two regions described in the "Data

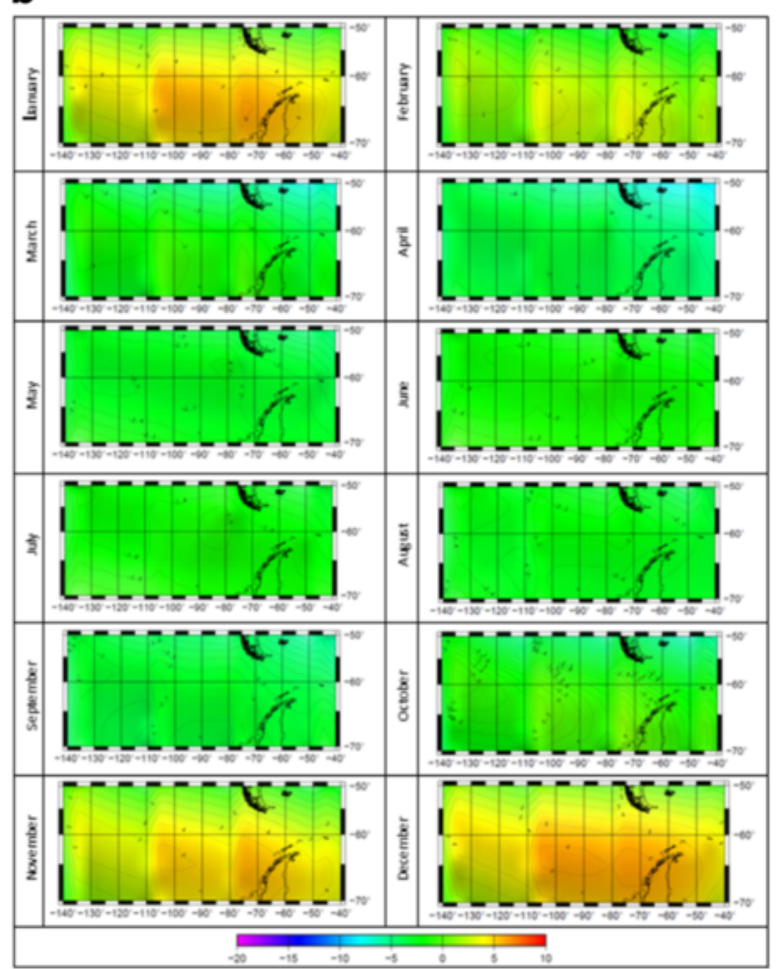

selection" section. One can see that mode 1 is having an average of $93 \%$ of the total observed variability. Considering that the first mode can be written as the product $\left(\mathbf{a}_{1} \cdot \mathbf{e}_{1}^{\mathrm{T}}\right)$, where $\mathbf{e}_{1}$ contains the spatial variation and $\mathbf{a}_{1}$ contains the temporal variation of the data set, the units of the product of $\mathbf{e}_{1}$ and $\mathbf{a}_{1}$ are in TECU ( 1 TECU $=10^{16}$ electrons $/ \mathrm{m}^{2}$ ). From Eq. (6), we can rewrite the values of VTEC as follows:

$$
\begin{aligned}
& \operatorname{VTEC}_{\text {night }}(t, x)=\overline{\operatorname{VTEC}}_{\text {night }}(x)+\left[\mathbf{a}_{1}(t) \mathbf{e}_{1}^{\mathrm{T}}(x)\right]_{\text {night }} \\
& \operatorname{VTEC}_{\text {noon }}(t, x)=\overline{\operatorname{VTEC}}_{\text {noon }}(x)+\left[\mathbf{a}_{1}(t) \mathbf{e}_{1}^{\mathrm{T}}(x)\right]_{\text {noon }}
\end{aligned}
$$

where $\mathrm{VTEC}_{\text {night }}$ and $\mathrm{VTEC}_{\text {noon }}$ are the synthetized data, $t$ the day of year, and $x$ is the geographical latitude and longitude.

In the following, we show the results of mode 1 PCA analysis along with the two periods representing low and high solar activity in both regions of interest. Figures 4, 5, 6, and 7 illustrate Eq. (7) showing the amplitude of the temporal variation, $\mathbf{a}_{1}$ (top), eigenvector or spatial variation, $\mathbf{e}_{1}$ (middle), and time average VTEC value 


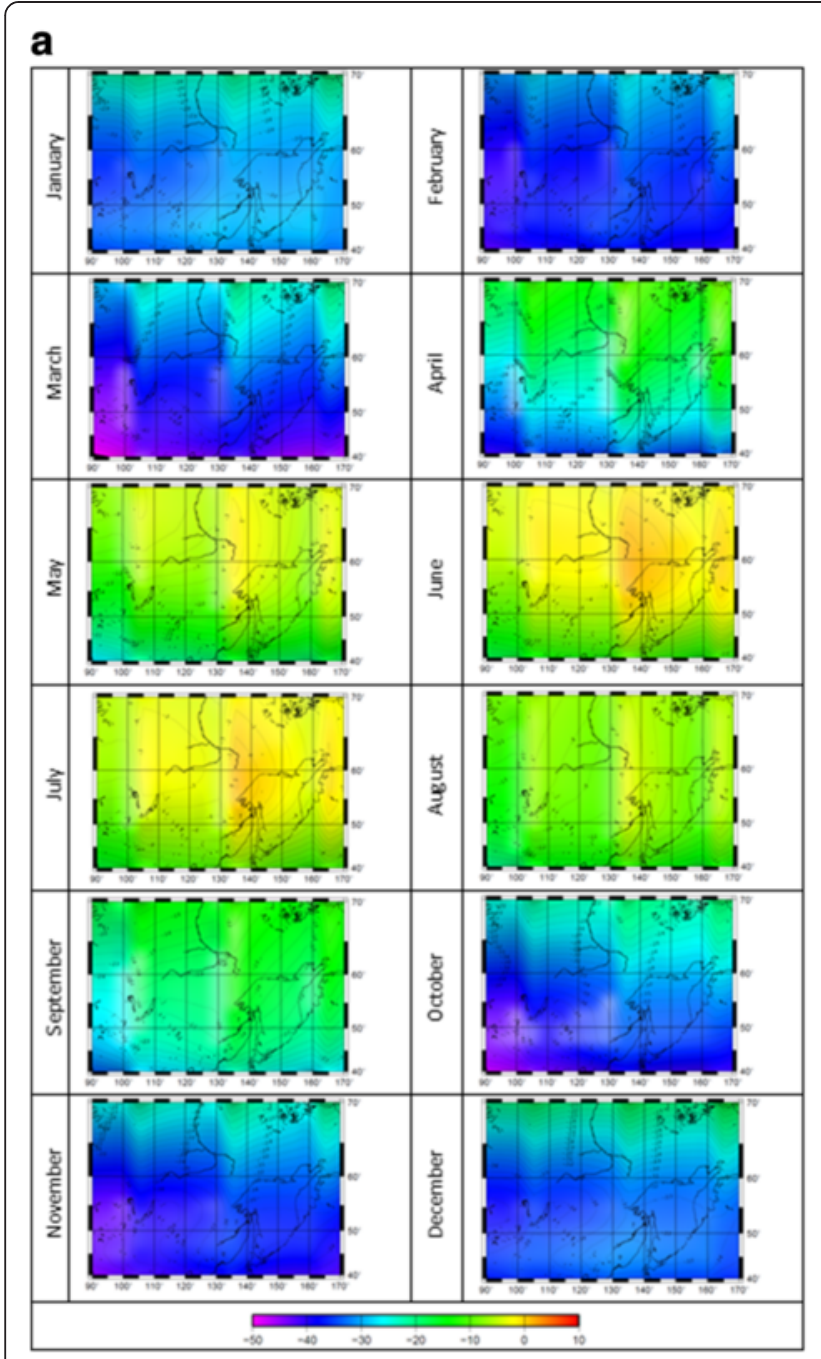

b

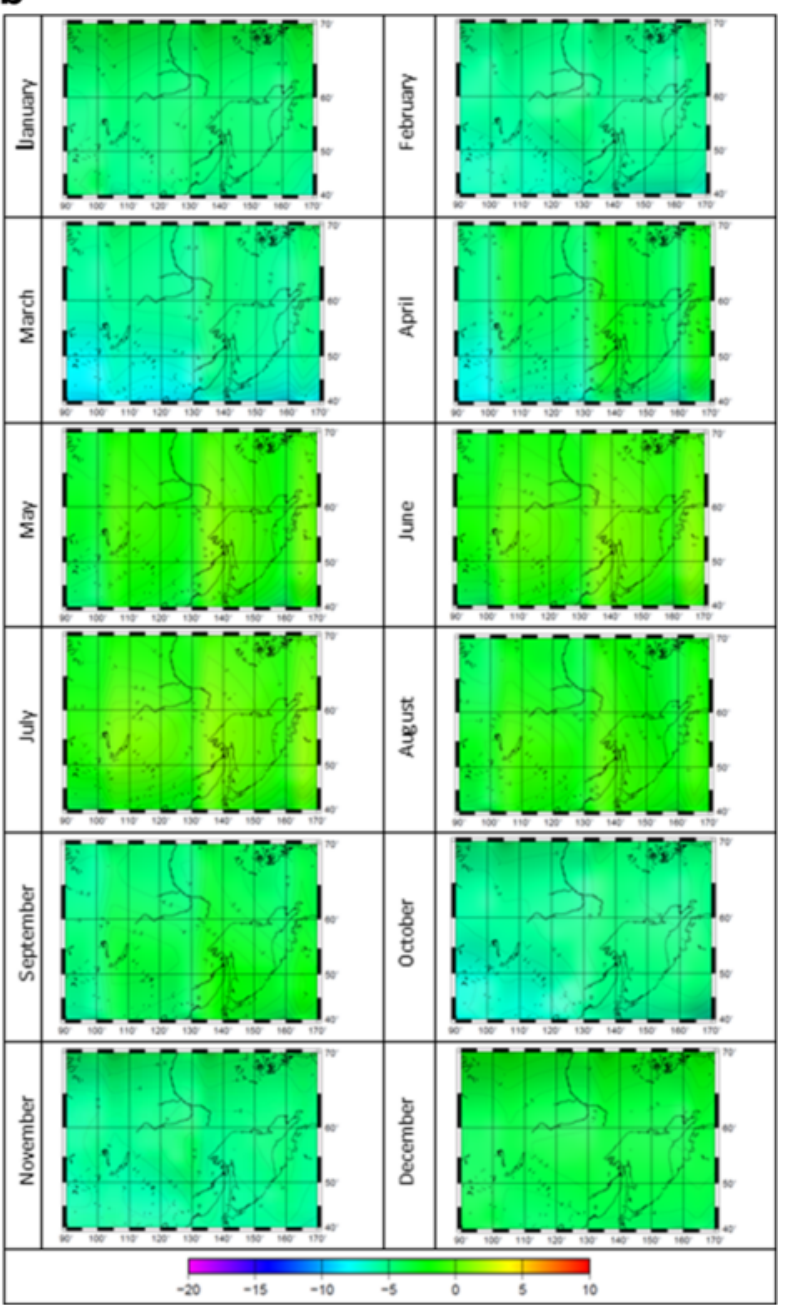

Fig. 2 Otkhotsk Sea region. a Differences between monthly averaged VTEC values at night and the respective ones at midday for high solar activity (2000-2002). Positive values indicate the anomaly. Colorbar units are in TECU. b Differences between monthly averaged VTEC values at night and the respective ones at midday for low solar activity (2006-2008). Positive values indicate the anomaly. Colorbar units are in TECU

(bottom). Figures 4 and 5 illustrate this during high and low solar activity, respectively, in the southern hemisphere, showing noon conditions (left) and night ones (right). Figures 6 and 7 are equivalent to Figs. 4 and 5 but for the northern hemisphere.

Focusing on the bottom of Figs. 4c, f, 5c, f, 6c, f, and $7 \mathrm{c}, \mathrm{f}$, we can see that performing the difference between time average VTEC values at night and at noon (first term of Eq. (7)) the result is always negative and this means there is no evidence of the anomaly. Therefore, the anomaly is mathematically expressed in the second term of Eq. (7). Thus, we will focus on the spatial and temporal variability of the first mode. Figure 4 allows us to analyze the first mode of PCA on VTEC for noon and night separately, during high solar activity at the Weddell Sea region. In Fig. 4d, we can see a strong annual variation at night with maximum value in summer, and a semiannual variation at midday with maximum values near the equinoxes is seen in Fig. 4a. Figure 5a, d shows the same as Fig. 4a, d but for low solar conditions. Here, there is also a strong annual variation at night with maximum value in summer, but the semiannual variation at midday is overlapped by an annual one (Natali and Meza 2010).

Figure 6 displays the first mode of PCA on VTEC showing noon and night during high solar activity in the Okhotsk Sea region. Figure 6d shows an annual variation at night with maximum values during summer, and a strong semiannual variation during midday is seen in Fig. 6a. This feature can also be seen during low solar activity (Fig. 7a, d). In this case, both components, annual and semiannual, have almost the same amplitude. The PCA method decomposes the information in spatial and temporal variation, and 

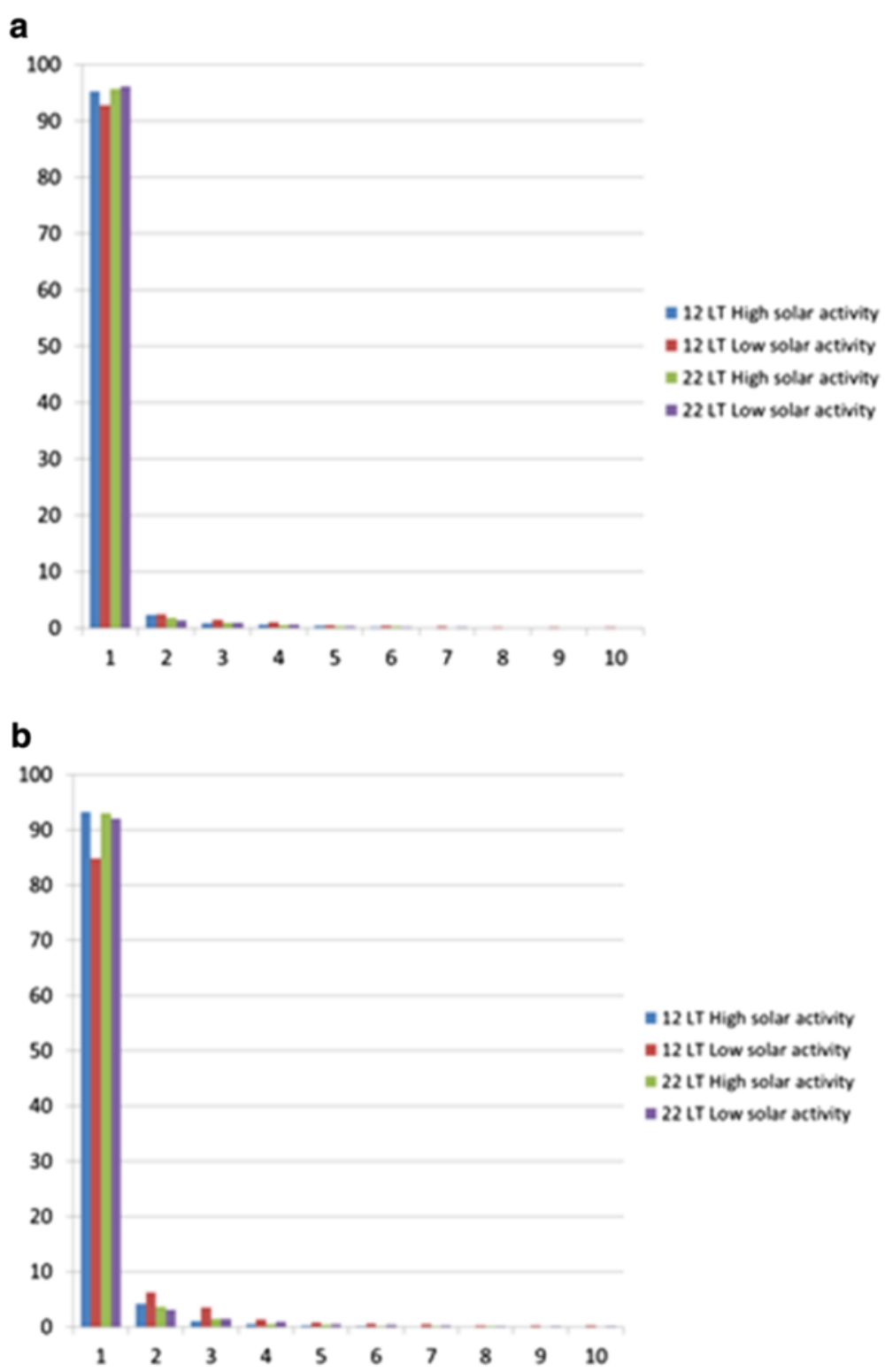

Fig. $\mathbf{3}$ a, $\mathbf{b}$ Variability percentage represented by the first ten modes for the eight selected 3-year map series for the southern and northern hemispheres, respectively

these features help us to infer the physical causes of the anomaly. To that end, we physically analyzed the components of the second term of Eq. (7), hereafter called variability.

With the objective of confirming that the observed phenomena only happens in the Weddell and Okhotsk Sea areas, the former analysis was repeated in two control regions at the same latitude and during the same periods of high and low solar activity conditions. The southern control region extends from $10^{\circ} \mathrm{E}$ to $110^{\circ} \mathrm{E}$ in longitude while the northern control area extends from $40^{\circ} \mathrm{W}$ to $40^{\circ} \mathrm{E}$. Additional files 1, 2, 3, 4, 5, 6, 7, and 8 resembled Figs. 4, 5, 6, 7, 8, and 9 but for the control zones aforementioned.

During high solar activity period, focusing on the adjacent Weddell Sea control area (not shown, Additional file 1$)$, we can observe that the variability $\left(\left[\mathbf{a}_{1}(t) \mathbf{e}_{1}^{\mathrm{T}}(x)\right]\right)$ at midday is comparable with respect to the corresponding values at the Weddell Sea area (Fig. 4), while at night, variability values in the control area are almost a half. On the other hand, pointing on the northern control area (Additional file 3), variability values at noon are comparable although at night they are almost $30 \%$ smaller than the respective values at the 


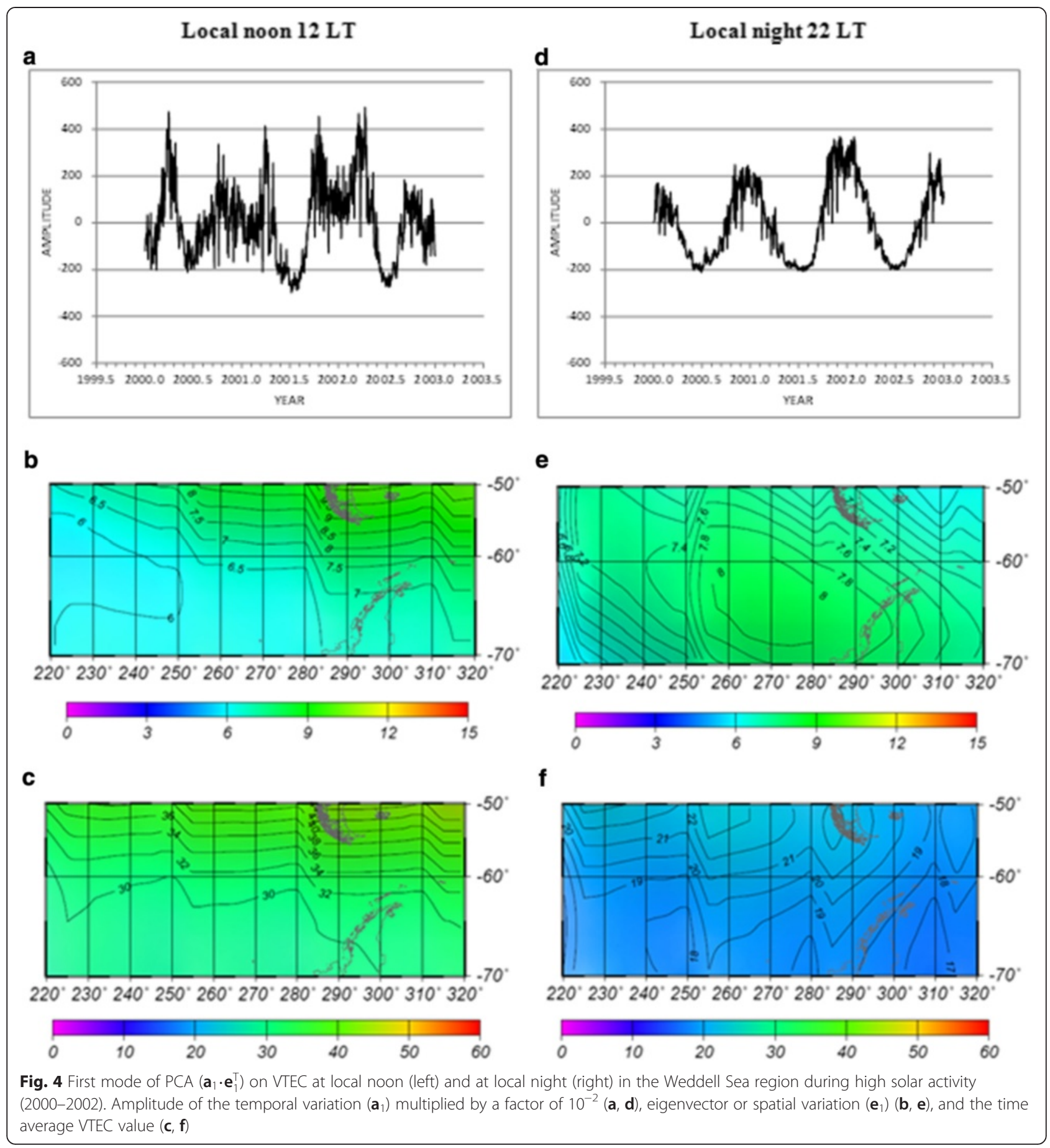

Okhotsk Sea area (Fig. 6). Thus from Eq. (7), in both cases, $\operatorname{VTEC}_{\text {night }}(t, x)$ results were always smaller than $\operatorname{VTEC}_{\text {noon }}(t, x)$, and consequently, they are not anomalous behaviors.

During low solar activity conditions, observing both variability and time average VTEC values at the southern control area (not shown, Additional file 2), we can see bigger values at midday and smaller values at night than the respective variables at the Weddell Sea (Fig. 5).
Moreover, in the northern control area (not shown, Additional file 4), variability at noon is similar but variability at night is slightly smaller than the respective values at the Okhotsk Sea area (Fig. 7). Again, VTECnight $(t, x)$ results were smaller than $\operatorname{VTEC}_{\text {noon }}(t, x)$ in both control areas showing that they are not anomalous behaviors.

From the analysis of the VTEC time variability (Figs. 4a, f, 5, 6, and 7a, f), we should conclude that the 


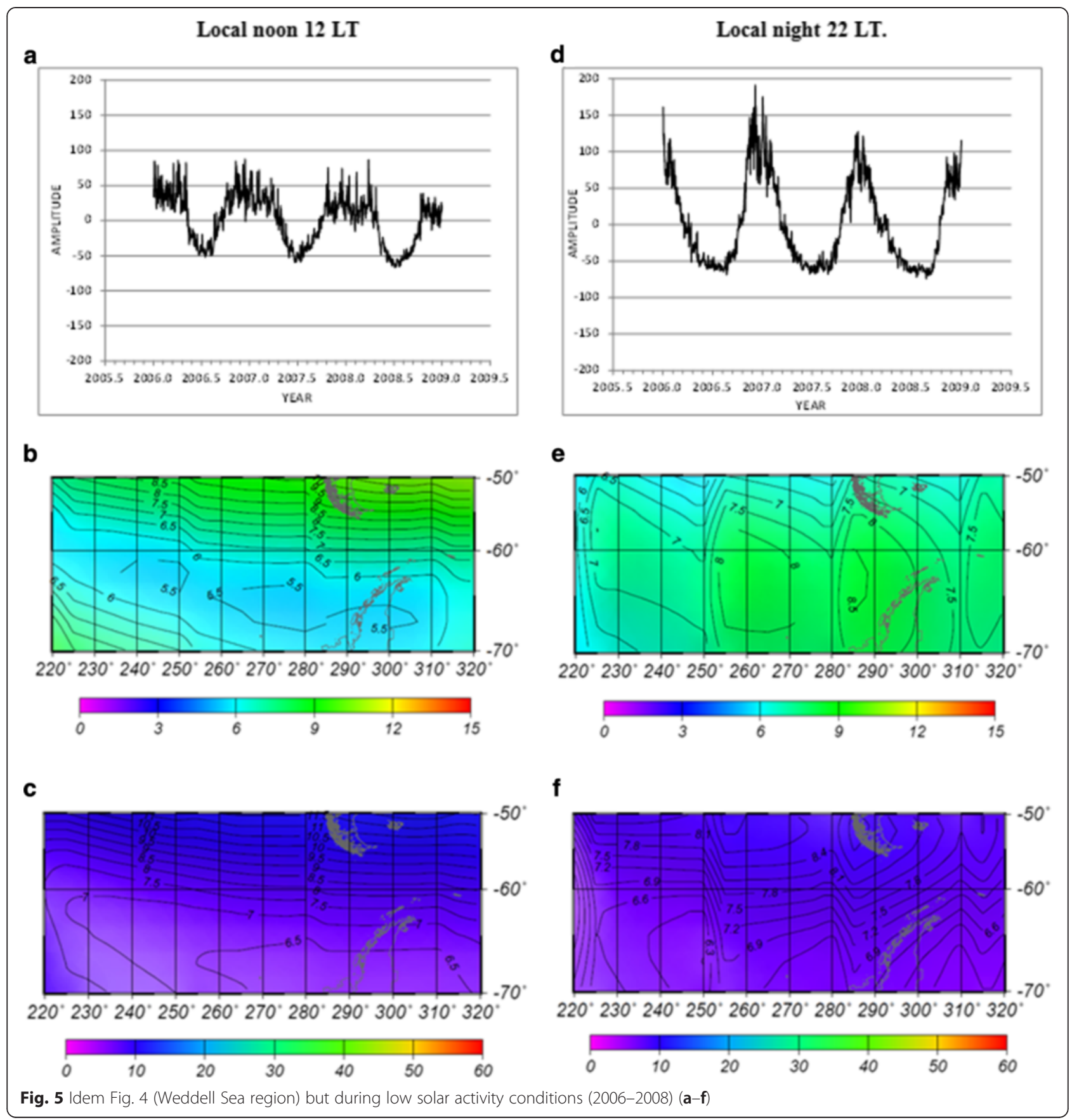

main contributions to the anomalies (WSA and OSA) are a combination of the same physical mechanisms that explain annual variation and semiannual anomaly in regions located far from the magnetic poles, i.e., the Asian and South Atlantic sectors (Rishbeth 1998). Millward et al. (1996) analyze the composition and meridional wind fields using a coupled thermosphere-ionosphereplasmasphere (CTIP) model in two locations in the southern hemisphere: one far from the pole and the other near the pole. They found from comparing the meridional component of the neutral air wind at noon that the poleward wind at the far-from-pole area was always greater in magnitude than the same wind component at the near-pole location. This situation specially occurs in winter where the difference is maximum (Fig. 5). Considering that the vertical velocity of ion can be described as $U^{*} \sin (I)^{*} \cos (I)$, where $U$ is the meridional wind and $I$ is the dip angle, and $I$ at the far-pole region is smaller than in other longitudes at the same geographical latitudes, therefore the vertical velocity 


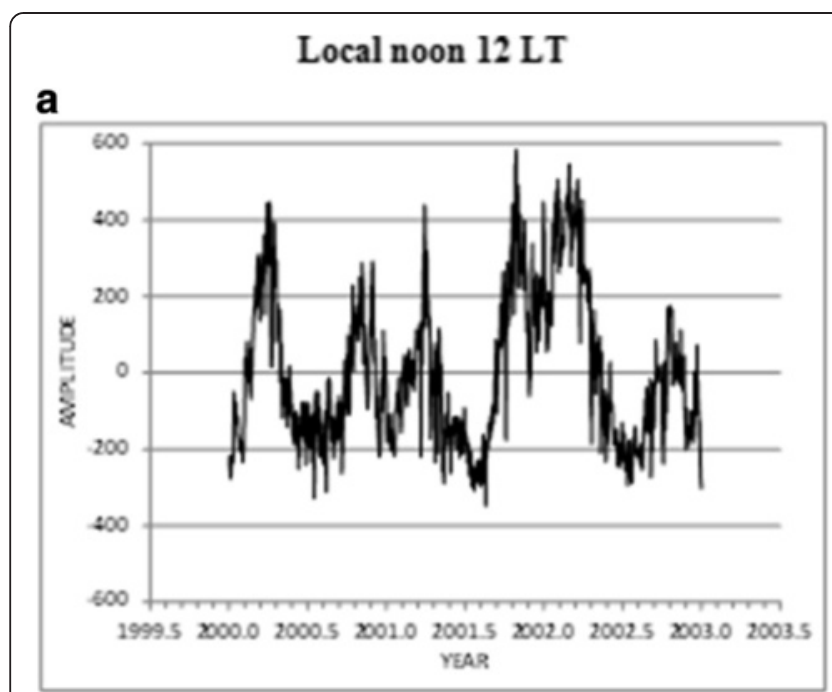

b

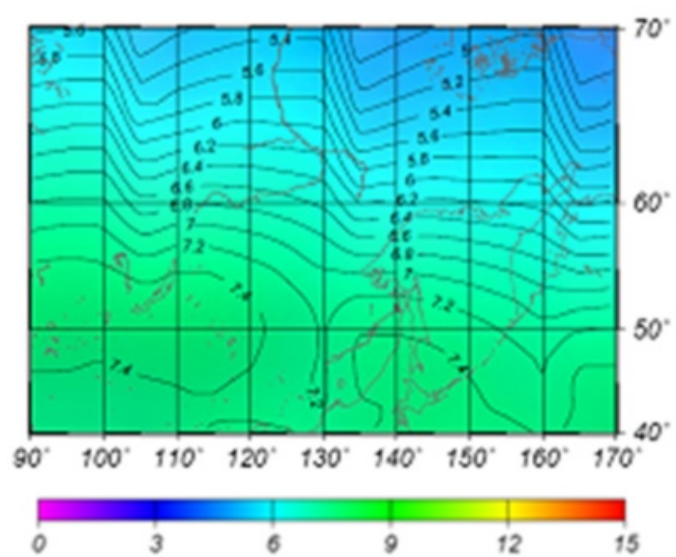

c

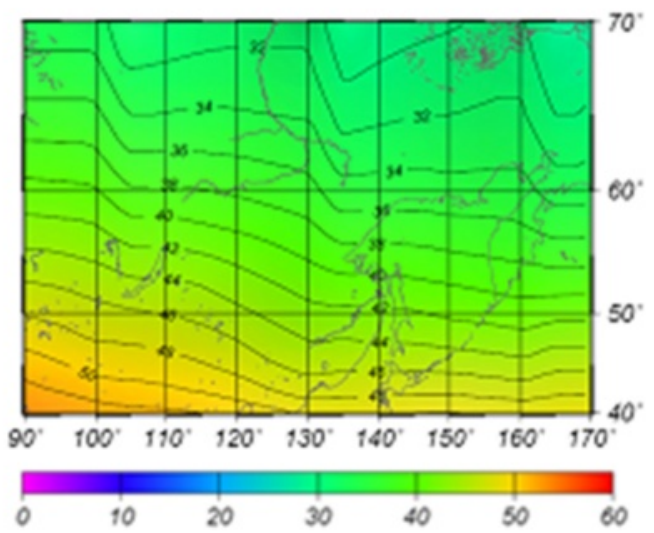

Local night $22 \mathrm{LT}$.

d

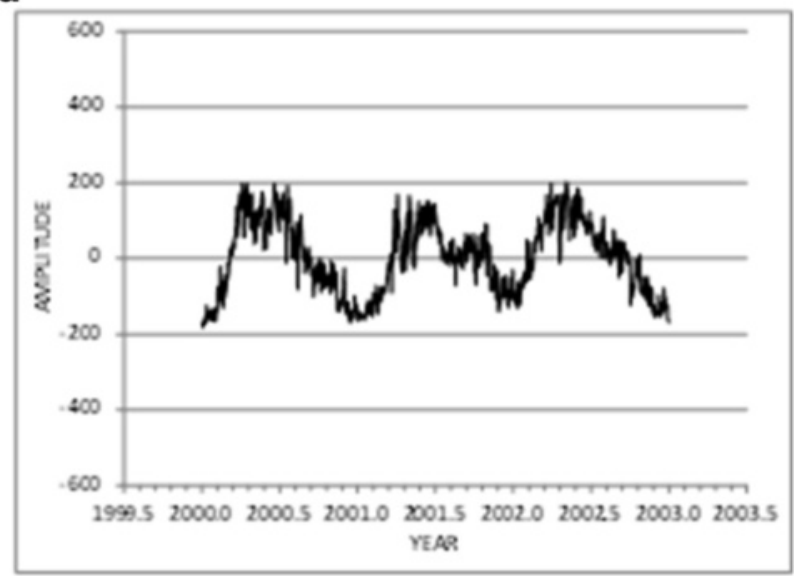

e

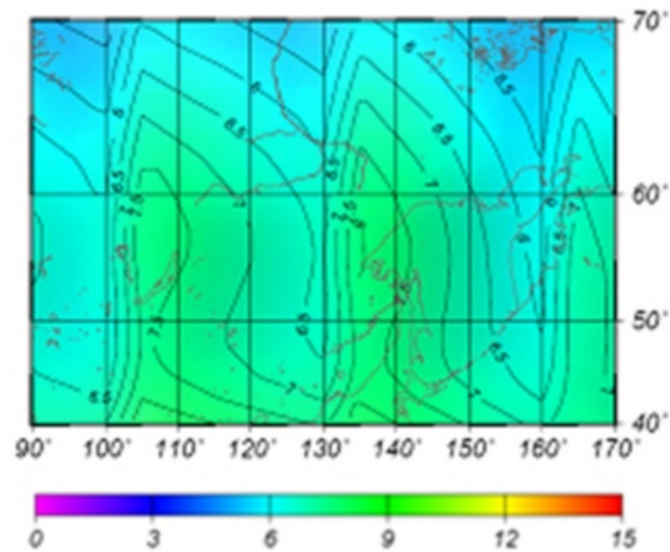

f

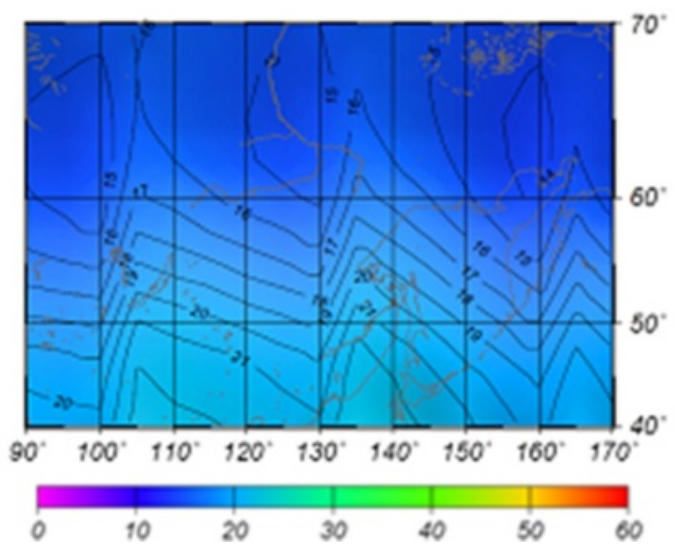

Fig. 6 First mode of PCA $\left(\mathbf{a}_{1} \cdot \mathbf{e}_{1}^{\top}\right)$ on VTEC at local noon (left) and at local night (right) in the Otkhotsk Sea region during high solar activity (2000-2002). Amplitude of the temporal variation $\left(\mathbf{a}_{1}\right)$ multiplied by a factor of $10^{-2}(\mathbf{a}$, $\mathbf{d})$, eigenvector or spatial variation $\left(\mathbf{e}_{1}\right)(\mathbf{b}$, e $)$, and the time average VTEC value $(\mathbf{c}, \mathbf{f})$

(downwelling due to poleward wind) of ion is larger at noon in the far-pole region than the near-pole region. Rishbeth and Müller-Wodarg (1999) also study the vertical circulation and thermospheric composition using the
CTIP model; they found that at noon in the winter hemisphere in longitude sectors far from magnetic poles, the downwelling motion occurs at lower latitudes of the auroral oval over a zone about $20^{\circ}$ wide, and the $\left[\mathrm{O} / \mathrm{N}_{2}\right]$ 


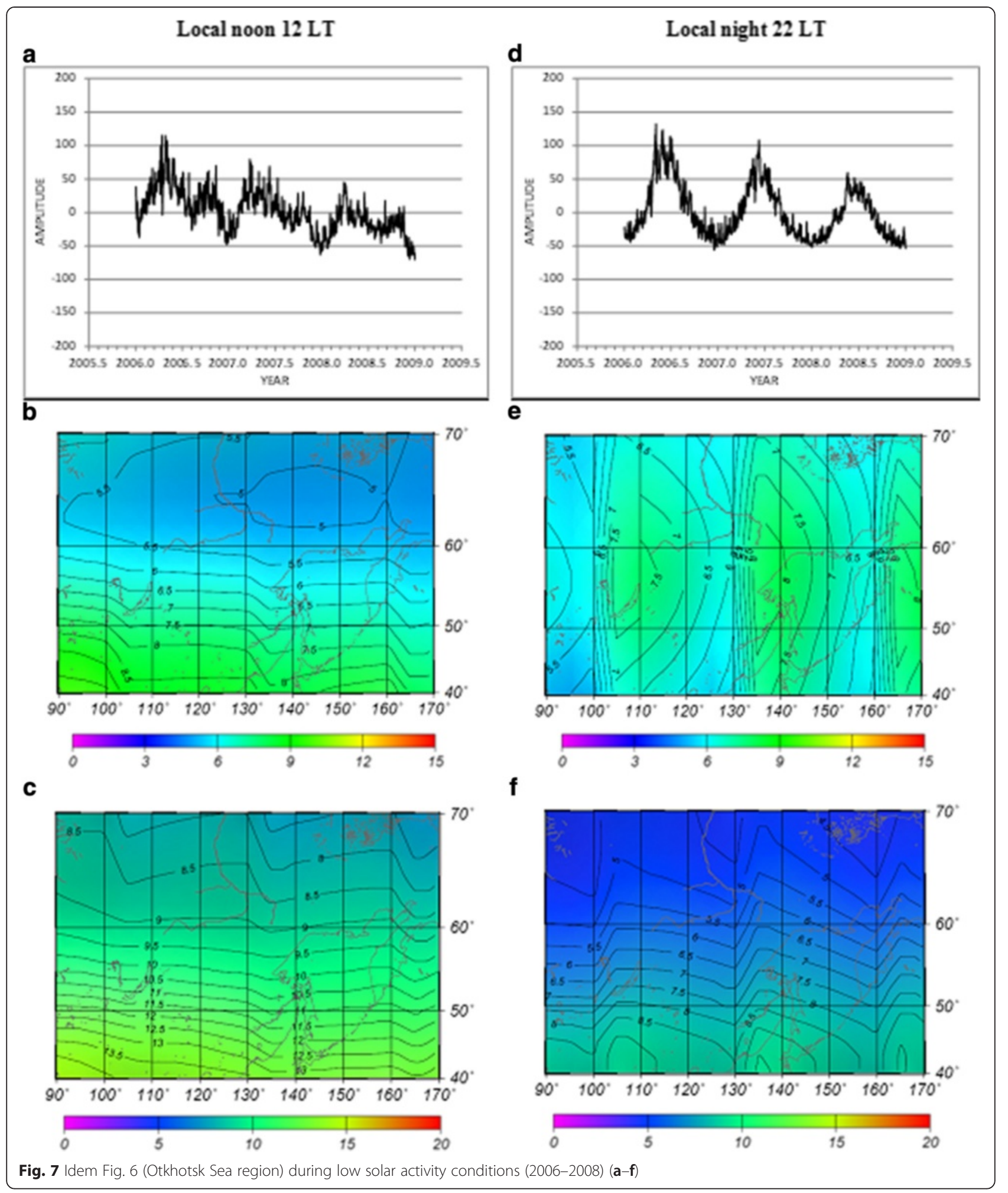

ratio is larger than in the near-pole sector longitudes, but the NmF2 is very small due to the lack of sunlight. Following Rishbeth 1998, in far-from-pole regions during winter, the downwelling region is in twilight or darkness at noon giving thus not enough ionizing radiation to increase the electron density. Then, the NmF2 rises from winter to equinox because the effect of the decreasing solar zenith angle is larger than the result 

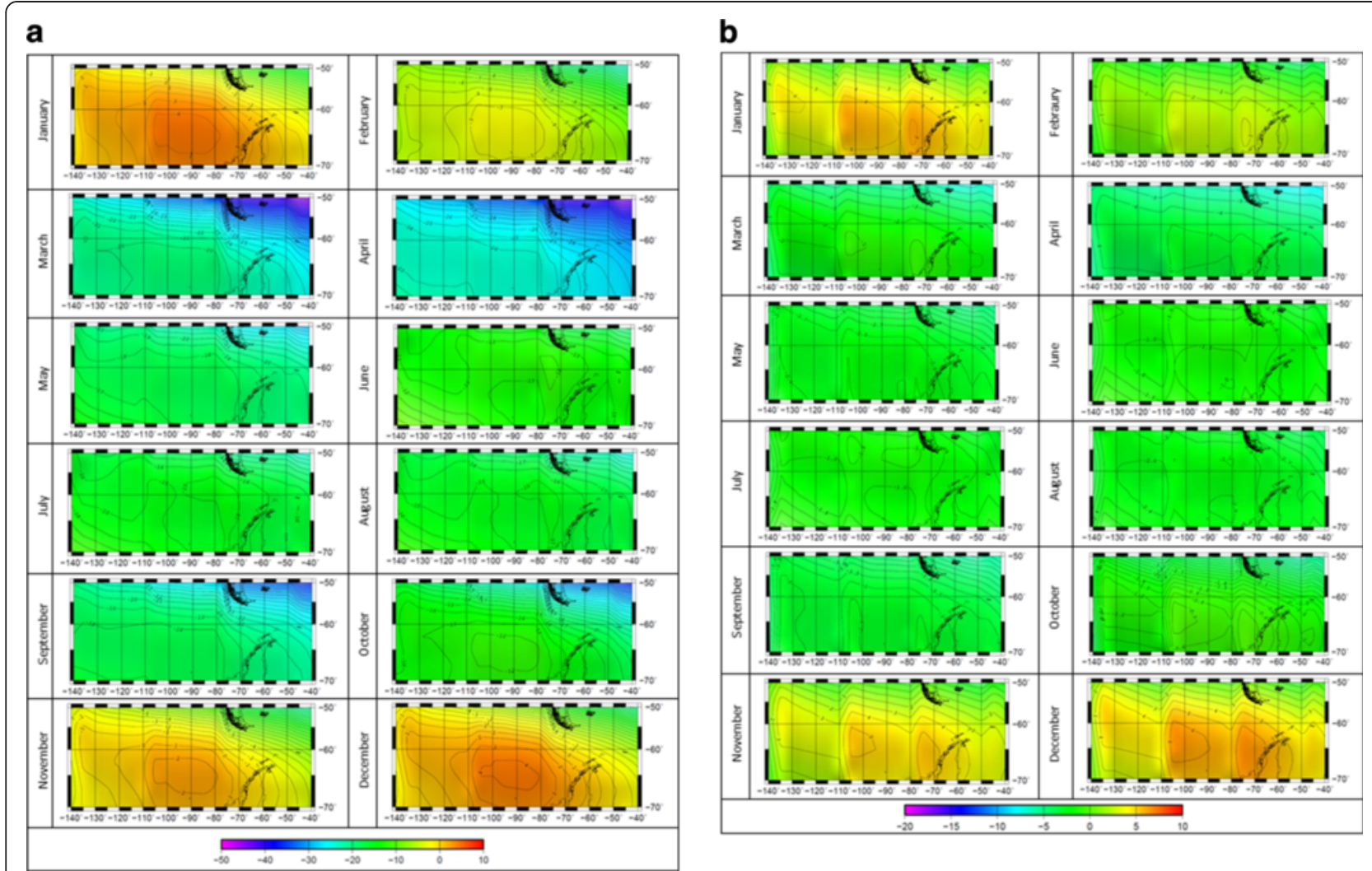

Fig. 8 Weddell Sea region. a Differences between monthly averaged estimated VTEC values from PCA synthesis (Eq. (7)) at night and the respective ones at midday during high solar activity (2000-2002). Positive values indicate the anomaly. Colorbar units are in TECU. b Differences between monthly averaged estimated VTEC values from PCA synthesis (Eq. (7)) at night and the respective ones at midday during low solar activity (2006-2008). Positive values indicate the anomaly. Colorbar units are in TECU

from changing the neutral air composition. Going from equinox noon to summer noon, there is not a great change in the solar zenith angle and the variations in $\left[\mathrm{O} / \mathrm{N}_{2}\right]$ have the great effect producing a decrease in NmF2 in summer. Thus, both effects combined justified the well-known observed semiannual anomaly.

On the other hand, in the far-from-pole region at night, the VTEC annual variation with maximum in summer is reinforced because the region is sunlight all night and the horizontal neutral winds blow towards the equator, which drive the ionization up the magnetic field lines (Millward et al. 1996; Rishbeth 1998; Fuller-Rowell 1998). The former causes explain the annual variation observed in the time series of the first mode PCA at local night (Figs. 4d, 5d, 6d, and 7d).

From the former comparison between Weddell and Okhotsk Sea regions with respect to their respective adjacent control areas, we could asseverate that the equatorward neutral winds in summer night plays an important role in the generation of both observed VTEC anomalies.

Therefore, looking at the components of the second term of Eq. (7), the combination of both effects in far- pole regions produces positive values of the difference between VTEC at night and the respective values at noon in both summer solstices and in southern spring during low solar activity. This conclusion reinforced the ideas previously expressed by Horvath (2006) and Jee et al. (2009) who asseverated that the most important factor to produce the WSA is the neutral wind effects on reducing the electron density during the day and enhancing the density at night. Following the same reasoning, OSA could also be explained.

In order to check the goodness of the PCA technique, we reconstruct the signal as shown in Figs. $8 \mathrm{a}, \mathrm{b}$ and $9 \mathrm{a}$, b. Figure 8a, b shows the maps that result from subtracting night-noon mode 1 PCA synthetized maps for WSA region using monthly average over the three respective years as shown in Fig. 1a, b. Note the similarity between these maps and the ones shown in Fig. 1a, b and the presence of WSA in January, November, and December for high solar activity and in January, February, November, and December for low solar activity.

Figure 9a, b is equivalent to Fig. 8a, b but for the northern hemisphere at OSA region. In this case, we also can see a clear correspondence with the maps 

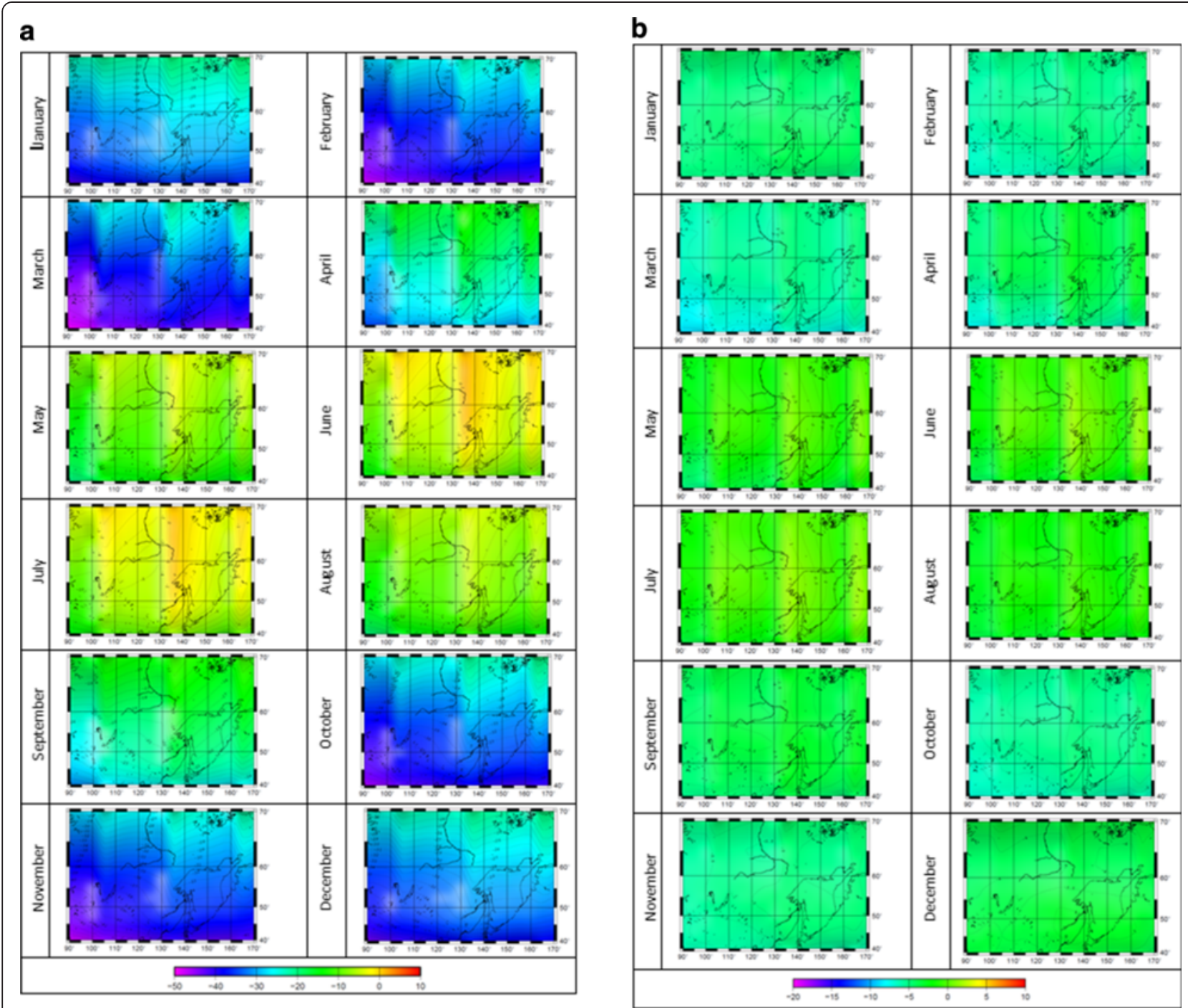

Fig. 9 Otkhotsk Sea region. a Differences between monthly averaged estimated VTEC values from PCA synthesis (Eq. (7)) at night and the respective ones at midday during high solar activity (2000-2002). Positive values indicate the anomaly. Colorbar units are in TECU. b Differences between monthly averaged estimated VTEC values from PCA synthesis (Eq. (7)) at night and the respective ones at midday during low solar activity (2006-2008). Positive values indicate the anomaly. Colorbar units are in TECU

shown in Fig. 2a, b. OSA is presented in June and July for high solar activity and in May, June, and July for low solar activity.

Finally, the goodness of the PCA technique was also tested in both control areas (not shown, Additional files $5,6,7$, and 8 . From these figures, we can see that the monthly average maps of the difference between mode 1 PCA synthetized VTEC values at night and the respective at noon (Eq. (7)) during high and low solar activity do not show anomalous VTEC behavior.

\section{Conclusions}

In this work, we use PCA analysis on IONEX data to highlight the existence of both WSA and OSA. This technique separates the main orthonormal component of the VTEC scattering. In this case, the first mode represents the $93 \%$ of the total VTEC variability, emphasizing the semiannual and annual ionospheric variations at noon and at night, respectively.

We found that the WSA is developed at the west of the Antarctic Peninsula over the Bellingshausen Sea and a similar anomaly is recorded in the northern hemisphere at high latitudes at about $130^{\circ} \mathrm{E}$ in longitude, referred here as Okhotsk Sea Anomaly (OSA).

When computing the difference between the time average VTEC values at $22 \mathrm{LT}$ and at $12 \mathrm{LT}$, it results negative and thus it is not anomalous. Instead, when adding the difference between the time average VTEC 
values at night and at noon to its spatial and temporal variability (Eq. (7)), the anomaly is shown. This anomalous behavior is present in both regions during summer in high and low solar activity and also in spring at the southern hemisphere during low solar activity.

In order to find out a physical explanation of the observed anomalies, we analyzed the time variations of the components of the second term of Eq. (7). We conclude that the main contributions to the anomalies (WSA and OSA) should be a combination of the same physical mechanisms that explain annual variation and semiannual anomaly in that regions located far from the magnetic poles. The most important factor is the neutral wind effect on reducing the electron density during the day and enhancing the density at night (Horvath 2006; Jee et al. 2009). In particular, we conclude that the equatorward neutral wind during nighttime could play an important role in the generation of these anomalies.

\section{Additional files}

Additional file 1: Figure S4. First mode of PCA in the adjacent Weddell Sea control area during high solar activity (2000-2002). First mode of PCA ( $\left.\mathbf{a}_{1} \cdot \mathbf{e}_{1}^{\top}\right)$ on VTEC at local noon (left) and at local night (right) in the adjacent Weddell Sea control area during high solar activity (2000-2002). Amplitude of the temporal variation ( $\mathbf{a}_{1}$ ) multiplied by a factor of $10^{-2}$ (top), eigenvector or spatial variation $\left(\mathbf{e}_{1}\right)$ (middle), and the time average VTEC value (bottom).

Additional file 2: Figure S5. First mode of PCA in the adjacent Weddell Sea control area during low solar activity (2006-2008). Idem Figure S4 (adjacent Weddell Sea control area) but during low solar activity conditions (2006-2008).

Additional file 3: Figure S6. First mode of PCA in the adjacent Otkhotsk Sea control area during high solar activity (2000-2002). First mode of PCA $\left(\mathbf{a}_{1} \cdot \mathbf{e}_{1}^{\top}\right)$ on VTEC at local noon (left) and at local night (right) in the adjacent Otkhotsk Sea control area during high solar activity (2000-2002). Amplitude of the temporal variation $\left(\mathbf{a}_{1}\right)$ multiplied by a factor of $10^{-2}$ (top), eigenvector or spatial variation ( $\left.\mathbf{e}_{1}\right)$ (middle), and the time average VTEC value (bottom).

Additional file 4: Figure S7. First mode of PCA in the adjacent Otkhotsk Sea control area during low solar activity (2006-2008). Idem Figure S6 (adjacent Otkhotsk Sea control area) during low solar activity conditions (2006-2008).

Additional file 5: Figure S8a. Difference of mode 1 PCA synthetized maps between night and noon for the adjacent WSA region using monthly average during high solar activity. Adjacent Weddell Sea region: differences between monthly averaged estimated VTEC values from PCA synthesis (Eq. (7)) at night and the respective ones at midday during high solar activity (2000-2002).

Additional file 6: Figure S8b. Difference of mode 1 PCA synthetized maps between night and noon for the adjacent WSA region using monthly average during low solar activity. Adjacent Weddell Sea region: differences between monthly averaged estimated VTEC values from PCA synthesis (Eq. (7)) at night and the respective ones at midday during low solar activity (2006-2008).

Additional file 7: Figure S9a. Difference of mode 1 PCA synthetized maps between night and noon for the adjacent Otkhotsk region using monthly average during high solar activity. Adjacent Otkhotsk Sea region: differences between monthly averaged estimated VTEC values from PCA synthesis (Eq. (7)) at night and the respective ones at midday during high solar activity (2000-2002).

Additional file 8: Figure $\mathbf{5 9 b}$. Difference of mode 1 PCA synthetized maps between night and noon for the adjacent Otkhotsk region using monthly average during low solar activity. Adjacent Otkhotsk Sea region: differences between monthly averaged estimated VTEC values from PCA synthesis (Eq. (7)) at night and the respective ones at midday during low solar activity (2006-2008).

\section{Competing interests}

The authors declare that they have no competing interests.

\section{Authors' contributions}

AM carried out the design of the study, performed the statistical analysis, and drafted the manuscript. MPN perfomed the numerical interpretation and drafted the manuscript. LIF carried out the physical interpretation and drafted the manuscript. All authors read and approved the final manuscript.

\section{Acknowledgements}

This research is supported by ANPCyT grant PICT 2012-1484 and UNLP grant G123. The authors thank the International GNSS Service (ftp:// cddis.gsfc.nasa.gov) for providing the IONEX data. The authors are grateful to the anonymous reviewers for the corrections and suggestions that improved this paper.

Received: 14 October 2014 Accepted: 23 June 2015

Published online: 04 July 2015

\section{References}

Bellchambers WH, Piggott WR (1958) lonospheric measurements made at Halley Bay. Nature 182:1596-1597. doi:10.1038/1821596a0

Burns AG, Zeng Z, Wang W, Lei J, Solomon SC, Richmond AD, Killeen TL, Kuo Y-H (2008) Behavior of the F2 peak ionosphere over the South Pacific at dusk during quiet summer conditions from COSMIC data. J Geophys Res 113:A12305. doi:10.1029/2008JA013308

Chapman S (1931) The absorption and dissociatival or ionizing effect of monochromatic radiation in atmosphere on a rotating earth. Proc Phys Soc 43:483-501

Chen CH, Huba JD, Saito A, Lin CH, Liu JY (2011) Theoretical study of the ionospheric Weddell Sea Anomaly using SAMI2. J Geophys Res 116:A04305. doi:10.1029/2010JA015573

Dudeney JR, Piggott WR (1978) Antarctic ionospheric research. Upper atmosphere research in Antarctica. In: Lanzerotti L, Park CG (eds) Antarct. Res. Ser, 29th edn. AGU, Washington, D. C., pp 200-235

Fuller-Rowell TJ (1998) The "thermospheric spoon": a mechanism for the semiannual density variation. J Geophys Res: Space Physics 103(A3):3951-3956

He M, Liu L, Wan W, Ning B, Zhao B, Wen J, Yue X, Le H (2009) A study of the Weddell Sea Anomaly observed by FORMOSAT-3/COSMIC. J Geophys Res 114:A12309. doi:10.1029/2009JA014175

Horvath I (2006) A total electron content space weather study of the nighttime Weddell Sea Anomaly of 1996/1997 southern summer with TOPEX/Poseidon radar altimetry. J Geophys Res 111:A12317. doi:10.1029/2006JA011679

Horvath I, Essex EA (2003) The Weddell Sea Anomaly observed with the TOPEX satellite data. J Atmos Sol Terr Phys 65:693-706. doi:10.1016/S1364-6826(03)00083-X

Jee G, Burns AG, Kim Y-H, Wang W (2009) Seasonal and solar activity variations of the Weddell Sea Anomaly observed in the TOPEX total electron content measurements. J Geophys Res 114:A04307. doi:10.1029/2008JA013801

Lin $C H$, Liu JY, Cheng CZ, Chen CH, Liu CH, Wang W, Burns AG, Lei J (2009) Three-dimensional ionospheric electron density structure of the Weddell Sea Anomaly. J Geophys Res 114:A02312. doi:10.1029/2008JA013455

Lin CH, Liu CH, Liu JY, Chen CH, Burns AG, Wang W (2010) Midlatitude summer nighttime anomaly of the ionospheric electron density observed by FORMOSAT-3/COSMIC. J Geophys Res 115:A03308. doi:10.1029/2009JA014084

Liu H, Yamamoto M (2011) Weakening of the mid-latitude summer nighttime anomaly during geomagnetic storms. Earth Planets Space 63:371-375 
Liu H, Thampi SV, Yamamoto M (2010) Anomalous phase reversal of the diurnal cycle in the mid-latitude ionosphere. J Geophys Res 115:A01305 doi:10.1029/2009JA014689

Meza A, Natali MP (2008) Annual and semiannual TEC effects at low solar activity in midlatitude Atlantic region based on TOPEX. J Geophys Res 113:D14115, $11 \mathrm{pp}$

Millward GH, Rishbeth HH, Fuller-Rowell TJ, Aylward AD, Quegan S, Moffett RJ (1996) lonospheric F 2 layer seasonal and semiannual variations. J Geophys Res: Space Physics 101(A3):5149-5156

Natali MP, Meza A (2010) Annual and semiannual VTEC effects at low solar activity based on GPS observations at different geomagnetic latitudes. J Geophys Res 115:D18106. doi:10.1029/2010JD014267

Penndorf R (1965) The average ionospheric conditions over the Antarctic. In: Waynick AH (ed) Geomagnetism and aeronomy: studies in the ionosphere, geomagnetism and atmospheric radio noise, Antarct Res Ser, vol. 4. AGU, Washington, D. C., pp 1-45. doi:10.1029/AR004p0001

Preisendorfer RW (1988) Principal component analysis in meteorology and oceanography. Elsevier, Amsterdam, p 424

Rishbeth H (1998) How the thermospheric circulation affects the ionospheric F2-layer. J Atmos and Solar-Terrestrial Physics 60(14):1385-1402

Rishbeth H, Müller-Wodarg ICF (1999) Vertical circulation and thermospheric composition: a modeling study. Ann Geophysicae 17:794-805

Schaer S, Beutler G, Rothacher M (1998) Mapping and predicting the ionosphere. Proceedings of the IGS AC Workshop. Darmstadt, Germany

Wackernagel H (1998) Multivariate geostatistics: an introduction with applications, 2nd edition, 291 pp. Springer, Berlin

Zhao B, Wan W, Liu L, Yue X, Venkatraman S (2005) Statistical characteristics of the total ion density in the topside ionosphere during the period 1996-2004 using empirical orthogonal function (EOF) analysis. Ann Geophys 23:3615-3631. doi:10.5194/angeo-23-3615-2005

\section{Submit your manuscript to a SpringerOpen ${ }^{\circ}$} journal and benefit from:

- Convenient online submission

- Rigorous peer review

- Immediate publication on acceptance

- Open access: articles freely available online

- High visibility within the field

- Retaining the copyright to your article

Submit your next manuscript at $>$ springeropen.com 